LBNL-49412

\title{
A Density Functional Theory Study of the Oxidation of Methanol to Formaldehyde over Vanadia Supported on Silica, Titania, and Zirconia
}

\author{
Rustam Z. Khaliullin and Alexis T. Bell* \\ Chemical Sciences Division \\ Lawrence Berkeley National Laboratory \\ and \\ Department of Chemical Engineering \\ University of California \\ Berkeley, CA 94720-1462
}

Submitted to

Journal of Physical Chemistry

January 10,2002

*To whom correspondence should be sent: bell@cchem.berkeley.edu 


\begin{abstract}
Density functional theory was used to investigate the mechanism and kinetics of methanol oxidation to formaldehyde over vanadia supported on silica, titania, and zirconia. The catalytically active site was modeled as an isolated $\mathrm{VO}_{4}$ unit attached to the support. The calculated geometry and vibrational frequencies of the active site are in good agreement with experimental measurements both for model compounds and oxidesupported vanadia. Methanol adsorption is found to occur preferentially with the rupture of a V-O-M bond $(\mathrm{M}=\mathrm{Si}, \mathrm{Ti}, \mathrm{Zr})$ and with preferential attachment of a methoxy group to V. The vibrational frequencies of the methoxy group are in good agreement with those observed experimentally as are the calculated isobars. The formation of formaldehyde is assumed to occur via the transfer of an $\mathrm{H}$ atom of a methoxy group to the $\mathrm{O}$ atom of the $\mathrm{V}=\mathrm{O}$ group. The activation energy for this process is found to be in the range of 199$214 \mathrm{~kJ} / \mathrm{mol}$ and apparent activation energies for the overall oxidation of methanol to formaldehyde are predicted to lie in the range of $112-123 \mathrm{~kJ} / \mathrm{mol}$, which is significantly higher than that found experimentally. Moreover, the predicted turnover frequency (TOF) for methanol oxidation is found to be essentially independent of support composition, whereas experiments show that the TOF is $10^{3}$ greater for titania- and zirconia-supported vanadia than for silica-supported vanadia. Based on these findings, it is proposed that the formation of formaldehyde from methoxy groups may require pairs of adjacent $\mathrm{VO}_{4}$ groups or $\mathrm{V}_{2} \mathrm{O}_{7}$ dimer structures.
\end{abstract}




\section{Introduction}

Supported vanadia is an active catalyst for the selective oxidation of methanol to formaldehyde and consequently significant attention has been devoted to understanding the structure-activity relationship for such catalysts and the reaction kinetics. $1,2,3,4,5,6$ Investigations of the effects of vanadia coverage and support composition have revealed several interesting trends. For a given support, the turnover frequency (TOF) for formaldehyde formation is independent of vanadia coverage. While Raman studies show that the ratio of $\mathrm{V}-\mathrm{O}-\mathrm{V}$ bonds to terminal $\mathrm{V}=\mathrm{O}$ bonds increases with vanadia coverage on most oxide support, the absence of a change in the TOF with vanadia coverage suggests that $\mathrm{V}-\mathrm{O}-\mathrm{V}$ bonds are not involved in the oxidation of methanol. Therefore, it has been proposed that methanol oxidation to formaldehyde can occur on isolated sites. By contrast, a variation in the TOF of approximately four orders of magnitude is observed with changes in the composition of the support $\left(\mathrm{CeO}_{2}>\mathrm{ZrO}_{2} \sim \mathrm{TiO}_{2}>\mathrm{Nb}_{2} \mathrm{O}_{5}>\mathrm{Al}_{2} \mathrm{O}_{3}>\right.$ $\left.\mathrm{SiO}_{2}\right) .{ }^{1,7,8}$ The strong dependence of the TOF on support composition suggests that the bridging V-O-M ( $\mathrm{M}$ = support metal atom) bonds control the catalyst activity. Consistent with this idea, the methanol oxidation TOF has been observed to decrease with an increase in the Sanderson electronegativity of the oxide support cation, suggesting that the reactivity of the oxygen atoms in the V-O-M bond decreases with decreasing basicity of the oxygen.

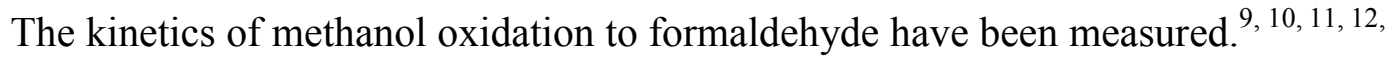
13 At low surface concentrations of adsorbed methanol, the rate of formaldehyde formation is proportional the partial pressure of methanol. The reaction is zero order in the partial pressure of oxygen when it presents in excess and vanadia sites are fully 
oxidized. For low methanol conversions and absence of water addition to the feed stream, the rate of formaldehyde formation is pseudo zero order in water. ${ }^{1,10}$ The effective rate coefficient can be represented as the product of the equilibrium constant for methanol adsorption and the rate coefficient for the oxidation of methoxy species to formaldehyde. ${ }^{10}$

A reaction mechanism has been proposed to interpret the observed kinetics. ${ }^{9}$ The first step in the sequence is envisioned to be protonation of the V-O-M bond with the consequent formation of a $\mathrm{V}-\mathrm{OCH}_{3}$ intermediate and $\mathrm{M}-\mathrm{OH}$. Formaldehyde is formed by the release of an $\mathrm{H}$ atom from $\mathrm{V}-\mathrm{OCH}_{3}{ }^{14,15}$ but the identity of the atom that receives the $\mathrm{H}$ atom has not been identified. ${ }^{15,16,17,18,19,20,21,22}$ Both steps in the mechanism are affected by the support composition. Experiments show that with increasing basicity of the bridging $\mathrm{O}$ atom, the strength of adsorption of the weakly acidic methanol molecule increases. Similarly, temperature-programmed decomposition studies of $\mathrm{V}-\mathrm{OCH}_{3}$ show that the temperature at which this species decomposes to form formaldehyde depends on the support composition. ${ }^{9}$

The aim of the present study was to investigate the effects of support composition on the adsorption of methanol on supported vanadia and the subsequent reaction of methoxy species on the formation of formaldehyde. $\mathrm{SiO}_{2}, \mathrm{TiO}_{2}$, and $\mathrm{ZrO}_{2}$ were considered as the supports. The active site for methanol synthesis was taken to be an isolated $\mathrm{VO}_{4}$ unit. Density functional theory (DFT) was used to determine the energetics of methanol adsorption and reaction. Total energies and vibrational frequencies determined from DFT calculations were used to compute equilibrium constants and rate coefficients. 


\section{Theoretical Methods}

The active center for methanol oxidation was represented by a distorted tetrahedral $\mathrm{VO}_{4}$ unit attached to silicon, titanium, or zirconium atoms, as shown in Figure 1. The dangling bonds at the edge of the cluster were terminated by $\mathrm{OH}$ groups. The distance between any two support atoms (i.e., Si, Ti, $\mathrm{Zr}$ ) was chosen based upon a consideration of the surface structure of the support. Several investigators have shown that the surface facets of $\beta$-crystoballite are a good model for silica. $23,24,25,26,27,28,29,30,31$ The most stable facet of $\beta$-crystoballite is the (111) surface, which is made up rings containing six $\mathrm{Si}$ atoms. Every other $\mathrm{Si}$ atom on the (111) surface of $\beta$-crystoballite is terminated by an $\mathrm{OH}$ group. ${ }^{30,} 32$ In the case of $\mathrm{TiO}_{2}$, the rutile phase exhibits predominantly (110) planes ${ }^{33,34,35,36,37}$ and in the case of $\mathrm{ZrO}_{2}$, the (101) planes are the most stable planes. ${ }^{38,39}$ For both $\mathrm{TiO}_{2}$ and $\mathrm{ZrO}_{2}$, each support atom can be connected to a hydroxyl group. ${ }^{37,38,39,40}$ The distance between the support atoms (see Figure 1) was taken from radial distribution functions obtained from XRD, NS, and EXAFS measurements. $^{41,42,43}$ Table 1 summarizes these results and indicates the distances between support atoms chosen for this work.

Density functional theory calculations were performed using the B3LYP functional. ${ }^{44,45,46}$ The 6-31 $\mathrm{g}$ basis set was used for all atoms except $\mathrm{Ti}, \mathrm{V}$, and $\mathrm{Zr}$. The Los Alamos National Laboratory (LANL) effective core potentials and associated basis sets were used for the latter three atoms. ${ }^{47}$ Coarse optimization was done using the Jaguar 4.0 suite of programs ${ }^{48}$ and final optimization and frequency calculations were carried out with the Gaussian 98 package. ${ }^{49}$ With the exception of the support atoms, all remaining atoms in the cluster were relaxed during the calculations of minimum energy 
structures and transition states. Additional calculations were carried out in which the support atoms were allowed to relax, together with all the other atoms in the cluster. In this instance, the geometry obtained for fixed support atoms was used as the initial guess. Adsorption equilibrium constants and rate constants were calculated using standard statistical mechanics and absolute rate theory. ${ }^{50,51}$ We used the harmonic approximation and included the contributions of the translational, rotational, and vibrational partition functions of all gaseous species participating in the reaction and the vibrational partition functions associated with the active center. Since the latter is part of the solid, translational and rotational partition functions for the catalyst were assumed to be equal in all states along the pathway. All molecules were assumed to be in the groundstate electronic and nuclear configurations. To exclude errors in the calculations of the vibrational partition functions due to low-frequency vibrations associated with the edges of the clusters, we applied the commonly used technique of assigning an arbitrarily high mass $\left(10^{6} \mathrm{amu}\right)$ to the support atoms. This allowed us to discern the modes of the support and the modes of active center. Only the modes of the active centers were included in the calculations of the vibrational partition functions.

\section{Results and Discussion}

\section{Active sites}

The calculated and experimentally observed bond distances for the $\mathrm{VO}_{4}$ unit bound to each support are presented in Table 2. In the case of silica as the support, there are several model compounds against which we can compare our results, ${ }^{52,53}$ as well experimental data for silica-supported vanadia. ${ }^{54}$ Good agreement is seen between the calculated and the experimentally observed values of the $\mathrm{V}=\mathrm{O}, \mathrm{V}-\mathrm{O}$, and $\mathrm{V}-\mathrm{M}$ bond 
distances and those observed for the model compounds and silica-supported vanadia. It is also noted that the M-M bond distance of $5 \AA$ assumed for our calculations lies between that for $\left(\mathrm{Ph}_{3} \mathrm{SiO}\right)_{3} \mathrm{~V}=\mathrm{O}$ and vanadium-containing silsesquioxane (molecular model c). The length of the $\mathrm{V}=\mathrm{O}$ and $\mathrm{V}-\mathrm{O}$ bonds does not change much with the change in support composition to titania or zirconia. In the case of $\mathrm{VO}_{4}$ bonded to titania, the $\mathrm{V}=\mathrm{O}$ bond distance is in good agreement with that observed experimentally, ${ }^{55}$ but the $\mathrm{V}-\mathrm{O}$ bond distance is shorter. We believe that that the calculated value is more accurate, since a V-O bond distance of $1.90 \AA$ seems too long for this type of bond.

As noted earlier, calculations were also conducted in which the M-M distance was allowed to relax. For these calculations the fully relaxed geometry in which the M-M distance was held constant was used as the initial point. The results of calculations conducted for a fully relaxed geometry showed little change in the M-M atom distances $(\sim 8 \%$ for $\mathrm{Si}-\mathrm{Si}$ and less than that for $\mathrm{Ti}-\mathrm{Ti}$ and $\mathrm{Zr}-\mathrm{Zr}$ ) and virtually no changes in the geometry of the $\mathrm{VO}_{4}$ unit.

The calculated frequencies for vibrations of the $\mathrm{V}=\mathrm{O}$ bond are also listed in Table 2. All of the values listed are based on a scale factor of 0.94 . This value was chosen to obtain agreement between the all electron calculations done for $\mathrm{VO}_{4}$ supported on $\mathrm{TiO}_{2}$ and similar calculations carried out with the LANL effective core potential and associated basis sets for V. For the all-electron calculations, a scale factor of 0.96 was used, as is commonly done for calculations with $6-31 \mathrm{~g}$ basis set. $^{56}$ It is evident from Table 2 that the calculated and observed $\mathrm{V}=\mathrm{O}$ vibrational frequencies agree to within several wavenumbers. Consistent with the experimental literature, our calculations show that the frequencies of the $\mathrm{V}=\mathrm{O}$ stretching vibrations for titania and zirconia-supported 
$\mathrm{VO}_{4}$ are nearly the same and are $5-10 \mathrm{~cm}^{-1}$ lower than that for silica-supported $\mathrm{VO}_{4}{ }^{6,54}$ $57,58,59,60,61$ Relaxation of the support atoms had no effect on the frequency of the $\mathrm{V}=\mathrm{O}$ bond.

\section{Methanol adsorption}

Three possible pathways were considered for the adsorption of methanol. The first two involve methanol adsorption with cleavage of a $\mathrm{V}-\mathrm{O}-\mathrm{M}$ bond to produce methoxy species on either the vanadium atom or on the support metal atom. The third pathway involves addition of methanol across the $\mathrm{V}=\mathrm{O}$ bond to form methoxy and hydroxyl groups connected to the vanadium atom. Calculations performed with a 3-21g basis set showed that the third pathway has a positive free energy of reaction at $500 \mathrm{~K}$ $\left(\Delta \mathrm{G}^{500}=+70 \mathrm{~kJ} / \mathrm{mol}\right)$, while the adsorption pathways involving cleavage of a $\mathrm{V}-\mathrm{O}-\mathrm{M}$ bond have large negative values for the free energy of reaction ( $\Delta \mathrm{G}^{500}=-60$ to $65 \mathrm{~kJ} / \mathrm{mol}$ ). Therefore, only the first two alternatives (see Figures 2) were used for more accurate calculations with larger basis sets.

Optimized structures of the adsorption complexes are given in Figure 2 for silicasupported vanadia. The structures of the adsorption complexes for titania- and zirconiasupported vanadia are not shown since the geometries of these complexes are approximately the same as that for silica-supported vanadia. For both modes of adsorption we considered two cases of adsorption structures that differ with respect to the relative positions of hydroxyl and methoxy groups (complexes $\mathrm{C} 1$ and $\mathrm{C} 1$ ', and complexes $\mathrm{C} 2$ and $\mathrm{C}^{\prime}$ ' in Figure 2). In complexes $\mathrm{C} 1$ ' and $\mathrm{C} 2$ these groups are close to each other and a hydrogen bond is formed between them. By contrast, the hydrogen bond 
exists between the support hydroxyl and the oxygen atom of $\mathrm{V}=\mathrm{O}$ bond in complex $\mathrm{C} 1$. There is no hydrogen bond in $\mathrm{C} 2$ '.

The calculated vibrational frequencies for methoxy species attached to either $\mathrm{V}$ or $\mathrm{M}$ are presented in Table 3, together with the experimentally observed values. ${ }^{6,9,60,62}$ All of the frequencies were calculated for the $\mathrm{Cl}^{\text {' }}$ structure shown in Fig. 2 and were scaled by a factor of 0.96 . The agreement between calculated and observed frequencies is much better for symmetric vibrations than for asymmetric vibrations. Since the experimentally observed asymmetric vibrations are weaker than the symmetric vibrations, accurate determination of the positions of these modes is more difficult, and this may account for the greater discrepancy between theory and experiment. It is observed that for both types of vibration, the calculated band positions for methoxy groups attached to $\mathrm{V}$ are essentially independent of the composition of the support, consistent with what is observed experimentally. For methoxy groups attached to a metal atom of the support, the frequency of the symmetric $\mathrm{C}-\mathrm{H}$ stretching mode for $\mathrm{CH}_{3}$ groups does not remain the same as that for methoxy groups attached to $\mathrm{V}$. When $\mathrm{VO}_{\mathrm{x}}$ is attached to $\mathrm{Zr}$ or $\mathrm{Ti}$, the frequency of the $v_{\mathrm{s}}{ }^{\mathrm{CH}_{3}}$ band is higher for methoxy groups attached to $\mathrm{V}$, but the opposite is true when the support element is Si. The patterns observed for all three supports are consistent in direction and magnitude with those seen experimentally.

The vibrational frequency of the $\mathrm{V}=\mathrm{O}$ bond following methanol adsorption is also listed in Table 3. A scaling factor of 0.94 was used for this vibrational mode, since, as noted earlier, the $\mathrm{V}$ atom is represented by the LANL core potential and associated basis set. Excellent agreement is observed in the position of this band when the methoxy group resides on $\mathrm{V}$ attached to either $\mathrm{Ti}$ or $\mathrm{Zr}$, but the calculated frequency is considerably 
lower than that observed when the support metal is $\mathrm{Si}^{6,60}$ No evident explanation can be given for this discrepancy at this time.

Methanol adsorption energies are given in Table 4 for four adsorption modes. The formation of methoxy groups on the vanadium atoms is energetically more favorable process than on the support atoms in the case of titania- and zirconia-supported vanadia, but is only slightly more favorable in the case of silica-supported vanadia. The relative position of methoxy and hydrogen groups does not affect adsorption energies much in case of complexes $\mathrm{C} 1$ and $\mathrm{C} 1$ '. The lack of hydrogen bond in complex $\mathrm{C} 2$ ' makes it relatively unstable.

Figure 3 shows plots of the surface coverage of methoxy species bonded to $\mathrm{V}$ atoms as a function of temperature for each of the three supports. These calculations were carried out assuming a Langmuir model of adsorption and a constant methanol partial pressure of $1,013 \mathrm{~Pa}(0.01 \mathrm{~atm})$. In all cases, the $\mathrm{C} 1$ ' structure was used for these calculations. The surface coverage of support-bonded methoxy groups is not shown since it is negligible at all temperatures. Also shown in Figure 3 are the experimentally observed coverages reported by Wachs and coworkers. ${ }^{9}$ Reasonable agreement between theory and experiment is observed for titania- and zirconia-supported $\mathrm{VO}_{\mathrm{x}}$ units, and very good agreement is observed for the ratio of coverages observed on these two supports. Since here is only one experimental point for silica supported vanadia, it is difficult to draw any conclusions about the accuracy of the calculations relative to experimental observation. ${ }^{62}$ The ratio of methoxy coverages for vanadia supported on $\mathrm{TiO}_{2}$ and $\mathrm{ZrO}_{2}$ relative to vanadia supported on $\mathrm{SiO}_{2}$ are presented in Figure 3, as well. The maximum value of the ratio is 4.2 for $\mathrm{VO}_{\mathrm{x}} / \mathrm{TiO}_{2}: \mathrm{VO}_{\mathrm{x}} / \mathrm{SiO}_{2}$ and 12 for $\mathrm{VO}_{\mathrm{x}} / \mathrm{ZrO}_{2}: \mathrm{VO}_{\mathrm{x}} / \mathrm{SiO}_{2}$. Thus, 
the dissociative adsorption of methanol is expected to occur preferentially on $\mathrm{VO}_{\mathrm{x}} / \mathrm{TiO}_{2}$ and $\mathrm{VO}_{\mathrm{x}} / \mathrm{ZrO}_{2}$ relative to $\mathrm{VO}_{\mathrm{x}} / \mathrm{SiO}_{2}$, consistent with experimental observation.

\section{Oxidation of methoxy species}

It has been hypothesized that the formation of formaldehyde involves the abstraction of a hydrogen atom from a methoxy group. ${ }^{15,14}$ Since the oxygen atom of the vanadyl groups is closest to the hydrogen of the methoxy group, we have assumed that it is the principal acceptor of the hydrogen. Figure 4 illustrates the reactant, transition state, and product states for the formation of formaldehyde. In all cases, the oxidation step involves migration of a hydrogen atom from the methoxy group to the oxygen atom of the vanadyl group. For all supports, frequency analysis of final optimized transition-state structure gives only one imaginary frequency.

Selected structural parameters are summarized in Table 5. The numbering of the atoms in this table is given in Figure 4. It can be seen from these data that the structure of the transition state is the virtually the same for all supports. Atomic distances do not differ by more than $0.05 \AA$ (the largest difference is for $\mathrm{C}-\mathrm{H} 1$ bond), bond angles do not differ by more than $1^{\circ}$, and Mulliken charges are within 0.04 au.

Activation energies for the formation of formaldehyde are shown in Table 6 . The lowest activation energy is that for silica-supported vanadia and the highest is for titaniasupported vanadia. However, the spread in values for all three supports is $<15 \mathrm{~kJ} / \mathrm{mol}$. At low temperatures the apparent activation energy is equal to the activation energy for the oxidation step, whereas at high temperatures, where the coverage of active sites by methoxy species is small, the apparent activation energy is given by the sum of the methanol adsorption energy and the activation energy for the rate-determining step. For 
intermediate temperatures, the apparent activation energy will lie between these extremes. Comparison of the calculated apparent activation energies with those reported by Deo et al. shows that for either method of determination, the predicted values are significantly larger than those determined from experiments. ${ }^{1}$

To establish whether the discrepancy in our estimates of the apparent activation energy might be due to inaccuracies in our method of calculating the activation energy for the formation of formaldehyde, we performed several additional calculations. The B3LYP functional used in our work is known to give accurate predictions of equilibrium energies and geometries but to be less accurate for predicting transition states. As an alternative we explored the use of the BH\&HLYP functional, which has been reported to yield transition-state energies comparable to those attained from second-order MollerPlesset perturbation theory. ${ }^{63,} 64$ Indeed this functional predicts activation energies 10-15 kJ/mol lower than those determined using the B3LYP functional. We also explored the consequences of keeping the distances between pairs of support atoms fixed. Allowing these atoms to undergo relaxation, together with all other atoms, reduces the activation barrier by another $7-9 \mathrm{~kJ} / \mathrm{mol}$ for all support. Changes in the pathway do not lead to any improvement in the activation energies. For example, the barrier for the migration of a hydrogen atom from the methoxy group to the vanadium atom is $253 \mathrm{~kJ} / \mathrm{mol}$. The possibility that formaldehyde is formed via transfer of a hydrogen atom from the methoxy group to an $\mathrm{O}$ atom in one of the $\mathrm{V}-\mathrm{O}-\mathrm{M}$ bonds was not consider because the transition state for such a pathway would be highly strained, giving rise very likely to an even higher activation energy than that reported here. 
Since the apparent activation energies observed experimentally and those determined from quantum calculations show relatively small differences for various supports, it would appear that the observed thousand fold difference in the TOF for formaldehyde formation over titania- and zirconia-supported vanadia compared to silicasupported vanadia involves factors other than those arising from the influence of the support composition on the properties of isolated $\mathrm{VO}_{4}$ groups. Consistent with this perspective, Table 6 shows that the apparent preexponential factor calculated from experimental data is $>10^{3}$ higher for titania- and zirconia-supported vanadia than for silica-supported vanadia. Our calculation (see Table 6) indicate that such a large variation in the apparent preexponential factor cannot be attributed to differences in the preexponential factors for methanol adsorption or the oxidation of methoxy groups to formaldehyde. This then suggests that the mechanism of formaldehyde formation from methoxy groups needs to be reexamined.

Reference to Table 5 reveals that the $\mathrm{O} 1-\mathrm{V}-\mathrm{O} 2$ bond angle undergoes a considerable change as the methoxy group goes from the reactant to transition state shown in Figure 4. This large change, together with the large change in the C-H1 bond distance may be responsible for the high activation energies reported in Table 6. One might expect the activation energy to be considerably smaller if the transfer of the $\mathrm{H}$ atom from the methoxy group were to involve the $\mathrm{O}$ atom in a $\mathrm{V}=\mathrm{O}$ bond on an adjacent $\mathrm{VO}_{4}$ groups. However, based on the work reported here, one would not expect to observe large variations in the apparent activation energy with support composition. Thus, to account for the observed differences in formaldehyde TOF with support composition, one would need to suggest, for example, that the fraction of $\mathrm{V}$ atoms present in isolated $\mathrm{VO}_{4}$ 
units versus adjacent pairs of $\mathrm{VO}_{4}$ units or $\mathrm{V}_{2} \mathrm{O}_{7}$ dimers is significantly higher for titaniaand zirconia-supported vanadia than for silica-supported vanadia. Consistent with this view, experimental studies have shown consistently that highly dispersed vanadia is present on silica only in the form of isolated $\mathrm{VO}_{4}$ units, whereas on titania and zirconia, vanadia is present as both isolated $\mathrm{VO}_{4}$ units of $\mathrm{VO}_{\mathrm{x}}$ oligomers. ${ }^{8}, 65$ Recent extended Huckel calculations by Ferreira and Volpe support this view. ${ }^{66}$ The authors report that on silica only monovanadate species are formed, whereas on titania monomers and dimers are present, the latter species being more abundant. This leads us to suggest that the principal cause for the large difference observed in the TOF of methanol oxidation to formaldehyde with support composition is due to the state of vanadia aggregation. The presence of a significant fraction of the dispersed vanadia as dimers and higher oligomers for vanadia dispersed on titania and zirconia at the lowest vanadia loadings investigated experimentally may account for the observed independence of the formaldehyde formation TOF with changes in vanadia loading.

As a test of the above hypothesis, we carried out calculations of the activation energy for the case in which an $\mathrm{H}$ atom from a methoxide group attached to a $\mathrm{V}$ atom of one vanadyl group is transferred to the $\mathrm{O}$ atom of a $\mathrm{V}=\mathrm{O}$ group in an adjacent $\mathrm{VO}_{4}$ unit. For zirconia-supported vanadia the calculated activation energy is $191 \mathrm{~kJ} / \mathrm{mol}$ and the corresponding apparent activation energy is now $95 \mathrm{~kJ} / \mathrm{mol}$. As seen from Table 6 , the calculated apparent activation energy compares favorably with the experimental value of $90 \mathrm{~kJ} / \mathrm{mol}$ (see Table 6). The reduction in the activation energy calculated for the case of two adjacent $\mathrm{VO}_{4}$ units relative to a single $\mathrm{VO}_{4}$ unit is attributable to the reduction in the strain of the transition-state complex. For example, the H-C-O bond angle formed by the 
$\mathrm{H}$ atom being transferred from the methoxide group and the $\mathrm{C}$ and $\mathrm{O}$ atoms in the methoxide group is $115.3^{\circ}$ for the case of two adjacent $\mathrm{VO}_{4}$ units and is $83.2^{\circ}$ for the case of a single $\mathrm{VO}_{4}$ unit.

\section{Conclusions}

Based on evidence from experimental studies a model has been proposed to explain the effect of support composition on the partial oxidation of methanol to formaldehyde. The active site is taken to be an isolated $\mathrm{VO}_{4}$ unit attached to the support $\left(\mathrm{SiO}_{2}, \mathrm{TiO}_{2}, \mathrm{ZrO}_{2}\right)$. Density functional theory calculations of the site geometries and vibrational frequencies are in good agreement with experiments. Methanol adsorption occurs via two mechanisms involving breaking of the $\mathrm{V}-\mathrm{O}-\mathrm{M}(\mathrm{M}=\mathrm{Si}, \mathrm{Ti}, \mathrm{Zr})$ bonds. Methoxy group bonding to the vanadium atom is preferred for all supports. The vibrational frequencies of adsorbed methoxy species are in good agreement with experiment. The calculated heat of adsorption is in the range of $88-96 \mathrm{~kJ} / \mathrm{mol}$. The calculated coverages of $\mathrm{CH}_{3} \mathrm{O}$ species also agree well with experimental data. Formaldehyde is assumed to form via the transfer of a hydrogen atom from a methoxy group bound to the vanadium atom to the vanadyl oxygen atom. The calculated activation energy for this process lies in the range of $199-215 \mathrm{~kJ} / \mathrm{mol}$. If the fraction of active sites occupied by methoxy groups is assumed to be small, the apparent activation energy is given by the sum of the calculated activation energy and the energy change upon adsorption. The apparent activation energies calculated this way are comparable for

all supports are comparable but are higher than those observed experimentally. Based on these results it is concluded that the strong dependence of the TOF for formaldehyde formation on support composition observed experimentally cannot be explained by the 
effects of the support on the local electronic properties of the active site. It is proposed that the reaction of methoxy groups to form formaldehyde may involve the transfer of a hydrogen atom from the methoxy group to the $\mathrm{V}=\mathrm{O}$ bond of an adjacent $\mathrm{VO}_{4}$ unit or one occurring in a dimer unit (i.e., $\mathrm{V}_{2} \mathrm{O}_{7}$ ). The activation energy for such a process is projected to be lower than that calculated in the present study because of the anticipated reduction in the strain of the transition state. This proposal is consistent with both experimental and theoretical studies showing that only isolated $\mathrm{VO}_{4}$ units are stable on $\mathrm{SiO}_{2}$ but dimer and oligomeric vanadia structures are preferred on $\mathrm{TiO}_{2}$ and $\mathrm{ZrO}_{2}$.

\section{Acknowledgements}

This work was supported by a grant from the Civilian Research and Development Foundation under grant RC1-2204 and by the Director of the Office of Basic Energy Sciences, Chemical Sciences Division, of the U.S. Department of Energy under contract DE-AC03-76-SF00098. 


\section{References}

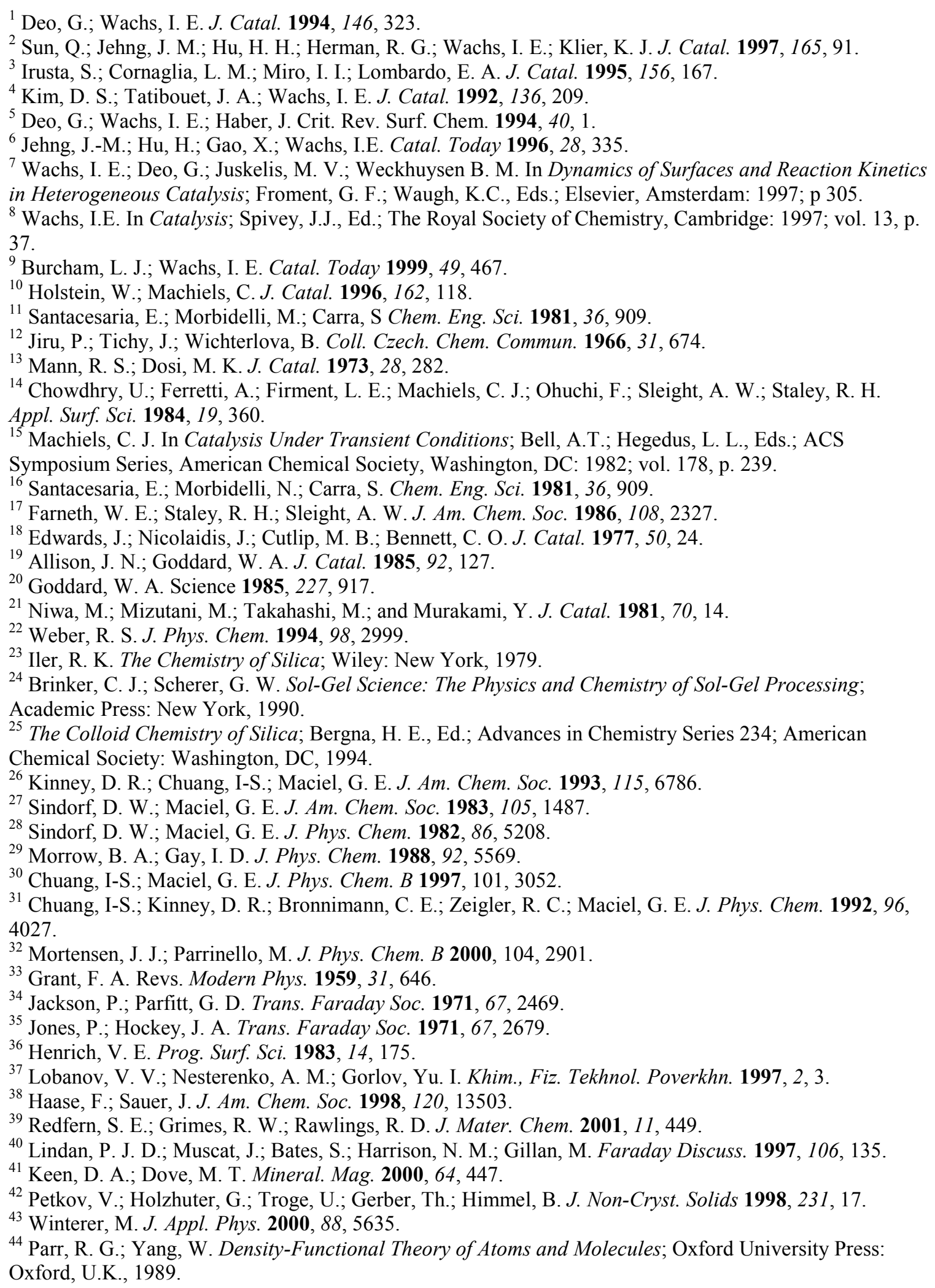


${ }^{45}$ Becke, A. D. J. Chem. Phys. 1993, 98, 5648.

${ }^{46}$ Lee, C.; Yang, W.; Parr, R. G. Phys. Rev. B 1988, 37, 785.

${ }^{47}$ Hay, P. J.; Wadt, W. R. J. Phys. Chem. 1985, 82, 299.

${ }^{48}$ Jaguar 4.1, Schrodinger, Inc., Portland, Oregon, 2000.

${ }^{49}$ Gaussian 98, Revision A.9, Frisch, M. J.; Trucks, G. W.; Schlegel, H. B.; Scuseria, G. E.; Robb, M. A.; Cheeseman, J. R.; Zakrzewski, V. G.; Montgomery, J. A.; Stratmann, R. E., Jr.; Burant, J. C.; Dapprich, S.; Millam, J. M.; Daniels, A. D.; Kudin, K. N.; Strain, M. C.; Farkas, O.; Tomasi, J.; Barone, V.; Cossi, M.; Cammi, R.; Mennucci, B.; Pomelli, C.; Adamo, C.; Clifford, S.; Ochterski, J.; Petersson, G. A.; Ayala, P. Y.; Cui, Q.; Morokuma, K.; Malick, D. K.; Rabuck, A. D.; Raghavachari, K.; Foresman, J. B.; Cioslowski, J.; Ortiz, J. V.; Baboul, A. G.; Stefanov, B. B.; Liu, G.; Liashenko, A.; Piskorz, P.; Komaromi, I.;

Gomperts, R.; Martin, R. L.; Fox, D. J.; Keith, T.; Al-Laham, M. A.; Peng, C. Y.; Nanayakkara, A.;

Challacombe, M.; Gill, P. M. W.; Johnson, B.; Chen, W.; Wong, M. W.; Andres, J. L.; Gonzalez, C.; HeadGordon, M.; Replogle, E. S.; Pople, J. A., Gaussian, Inc., Pittsburgh PA, 1998.

${ }^{50}$ McQuarrie, D. A. Statistical Mechanics; HarperCollins Publisher Inc.: New York, 1973.

${ }^{51}$ Hill, T. L. Statistical Thermodynamics; Dover Publications Inc.: New York, 1986.

${ }^{52}$ Feher, F. J.; Walzer, J. F. Inorg. Chem., 1991, 30, 1689.

${ }^{53}$ Rulkens, R.; Male, J. L.; Terry, K. W.; Olthof, B.; Khodakov, A.; Bell, A. T.; Iglesia, E.; Tilley, T. D. Chem. Mater. 1999, 11, 2966.

${ }^{54}$ Takenaka, S.; Tanaka, T.; Yamazaki, T.; Funabiki, T.; Yoshida, S. J. Phys. Chem. B 1997, 101, 9035.

${ }^{55}$ Kozlowski, R.; Pettifer, R. F.; Thomas, J. M. J. Phys. Chem., 1983, 87, 5176.

${ }^{56}$ Scott, A. P.; Radom, L. J. Phys. Chem. 1996, 100, 16502.

${ }^{57}$ Khodakov, A.; Olthof, B.; Bell, A. T.; Iglesia, E. J. Catal., 1999 181, 205.

${ }^{58}$ Gao, X.; Bare, S. R.; Weckhuysen, B. M.; Wachs, I.E. J. Phys. Chem. B 1998, 102, 10842.

${ }^{59}$ Olthof, B.; Khodakov, A.; Bell, A. T.; Iglesia, E. J. Phys. Chem. B 2000, 104, 1516.

${ }^{60}$ Burcham, L. J.; Deo, G.; Gao, X.; Wachs, I. E. Top. Catal. 2000, 11/12, 85.

${ }^{61}$ Wachs, I. E.; Deo, G; Weckhuysen, B. M.; Andreini, A.; Vuurman, M. A.; Boer, M de; Amiridis, M. D. J. Catal. 1996, 161, 211.

${ }^{62}$ Burcham, L. J.; Briand, L. E.; Wachs, I. E. Langmuir 2001, 17, 6164.

${ }^{63}$ Truong, T. N.; Duncan, W. T.; Bell, R. L. In Chemical Applications of Density-Functional Theory; Laird, B. B., Ross, R. B., Ziegler, T., Eds.; American Chemical Society: Washington, DC, 1996.

${ }^{64}$ Ryder, J. A.; Chakraborty, A. K.; Bell, A. T. J. Phys. Chem. B 2000, 104, 6998.

${ }^{65}$ Das, N.; Eckert, H.; Hu, H.; Wachs, I. E.; Walzer, J. F.; Feher, F. J. J. Phys. Chem. 1993, 97, 8240.

${ }^{66}$ Ferreira, M. L.; Volpe, M. J. Mol. Catal. A: Chem. 2000, 164, 281. 


\section{Figure Captions}

Fig. 1 Cluster models for representation of the active sites.

Fig. 2 Structures of methanol adsorption complexes

Fig. 3 Comparison of calculated and observed methanol adsorption isobars for $\mathrm{VO}_{\mathrm{x}} / \mathrm{SiO}_{2}, \mathrm{VO}_{\mathrm{x}} / \mathrm{TiO}_{2}, \mathrm{VO}_{\mathrm{x}} / \mathrm{ZrO}_{2}$

Fig. 4 Reactant, transition, and product states involved in the oxidation of a methoxy group to formaldehyde 
Figure 1 Cluster models for representation of the active sites

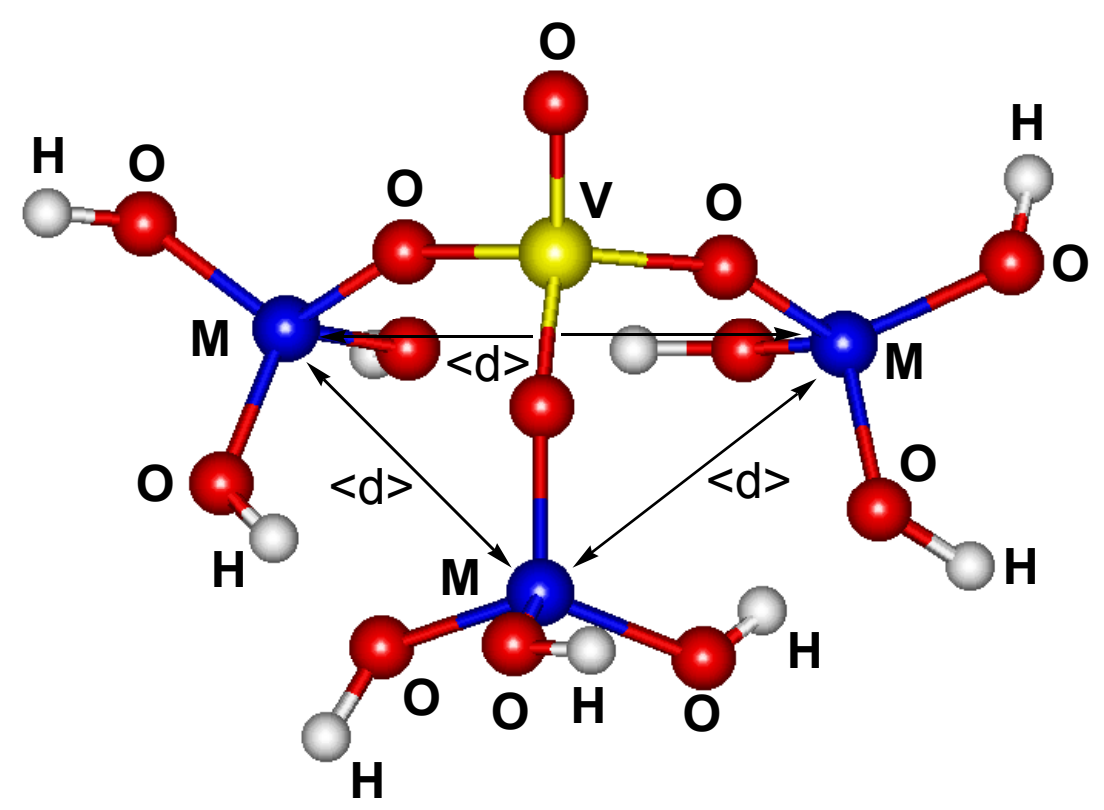


Table 1. M-M distances

\begin{tabular}{|l|c|c|c|c|}
\hline & Ref. & NN & NNN & Model \\
\hline$\beta$-cristobalite $\mathrm{SiO}_{2}, \AA$ & 41 & 3.1 & 5.0 & 5.00 \\
\hline bulk powders $\mathrm{TiO}_{2}, \AA$ & 42 & $3.5,3.9$ & 5.7 & 3.50 \\
\hline amorphous $\mathrm{ZrO}_{2}, \AA$ & 43 & $3.9-4.0$ & 7 & 3.90 \\
\hline
\end{tabular}


Table 2. Bond lengths and vibrational frequencies for the active sites.

\begin{tabular}{|c|c|c|c|c|c|c|c|c|c|c|}
\hline \multirow[b]{3}{*}{ Parameter } & \multicolumn{5}{|c|}{$\mathrm{VO}_{\mathrm{x}} / \mathrm{SiO}_{2}$} & \multicolumn{3}{|c|}{$\mathrm{VO}_{\mathrm{X}} / \mathrm{TiO}_{2}$} & \multicolumn{2}{|c|}{$\mathrm{VO}_{\mathrm{x}} / \mathrm{ZrO}_{2}$} \\
\hline & \multicolumn{4}{|c|}{ Observed } & \multirow{2}{*}{$\begin{array}{c}\text { Calculated } \\
\text { (effective } \\
\text { core } \\
\text { potential) }\end{array}$} & \multirow{2}{*}{$\begin{array}{c}\text { Observed } \\
\text { supported } \\
\text { VO }_{x}\end{array}$} & \multicolumn{2}{|c|}{ Calculated } & \multirow{2}{*}{$\begin{array}{c}\text { Observed } \\
\text { supported } \\
\text { VO }_{x}\end{array}$} & \multirow{2}{*}{$\begin{array}{c}\text { Calculated } \\
\text { (effective } \\
\text { core } \\
\text { potential) }\end{array}$} \\
\hline & $\begin{array}{c}\text { Model } \\
\text { compound } 1^{\mathrm{a}}\end{array}$ & $\begin{array}{c}\text { Model } \\
\text { compound } 2^{b}\end{array}$ & $\begin{array}{c}\text { Model } \\
\text { compound } 3^{\mathrm{c}}\end{array}$ & $\begin{array}{l}\text { Supported } \\
\text { VO }_{x}\end{array}$ & & & $\begin{array}{c}\text { Effective } \\
\text { core } \\
\text { potential }\end{array}$ & $\begin{array}{c}\text { All } \\
\text { electron }\end{array}$ & & \\
\hline $\mathrm{d}(\mathrm{V}=\mathrm{O}), \AA$ & 1.572 & 1.596 & 1.564 & 1.60 & 1.59 & 1.65 & 1.60 & 1.60 & - & 1.60 \\
\hline $\mathrm{d}(\mathrm{V}-\mathrm{O}), \AA$ & $1.743,1.745,1.739$ & 1.770 & $1.77,1.74,1.75$ & 1.79 & 1.77 & 1.90 & 1.76 & 1.77 & - & 1.77 \\
\hline $\mathrm{d}(\mathrm{M}-\mathrm{O}), \AA$ & $1.661,1.650,1.647$ & - & $1.65,1.65,1.64$ & - & 1.72 & - & 1.85 & 1.86 & - & 2.02 \\
\hline $\mathrm{d}(\mathrm{V}-\mathrm{M}), \AA$ & $3.311,3.260,3.349$ & - & $3.237,3.239,3.168$ & $3.38^{\mathrm{d}}$ & 3.40 & - & 3.22 & 3.22 & - & 3.44 \\
\hline $\mathrm{d}(\mathrm{M}-\mathrm{M}), \AA$ & $5.621,5.295,5.274$ & - & $4.550,4.563,4.826$ & - & 5.00 & - & 3.50 & 3.50 & - & 3.90 \\
\hline$v(\mathrm{~V}=\mathrm{O}), \mathrm{cm}^{-1}$ & - & 1038 & - & 1031-1039 & 1030 & $1022-1028$ & 1024 & 1024 & $1022-1028$ & 1022 \\
\hline Ref. & 52 & 53 & 52 & $\begin{array}{c}6,54,57,58 \\
59,60\end{array}$ & & $\begin{array}{c}55,57,59 \\
60\end{array}$ & & & 57,60 & \\
\hline
\end{tabular}

${ }^{a}$ Model compound 1: $\left(\mathrm{Ph}_{3} \mathrm{SiO}\right)_{3} \mathrm{~V}=\mathrm{O}$

${ }^{\mathrm{b}}$ Model compound 2: $\left((t-\mathrm{BuO})_{3} \mathrm{SiO}\right)_{3} \mathrm{~V}=\mathrm{O}$

${ }^{c}$ Model compound 3: $\left[\left(\mathrm{c}-\mathrm{C}_{6} \mathrm{H}_{11}\right)_{7}\left(\mathrm{Si}_{7} \mathrm{O}_{12}\right) \mathrm{V}=\mathrm{O}\right]_{2}$

${ }^{\mathrm{d}} \mathrm{V}-\mathrm{M}$ distance assigned originally to the $\mathrm{V}-\mathrm{V}$ distance 
Table 3. Vibrational analysis for methanol adsorption complexes.

\begin{tabular}{|c|c|c|c|c|c|c|c|c|c|c|c|c|}
\hline & \multicolumn{2}{|c|}{$\begin{array}{c}\mathrm{V}-\mathrm{OCH}_{3} \\
\text { for } \mathrm{VO}_{\mathrm{x}} / \mathrm{SiO}_{2}\end{array}$} & \multicolumn{2}{|c|}{$\mathrm{Si}-\mathrm{OCH}_{3}$} & \multicolumn{2}{|c|}{$\begin{array}{c}\mathrm{V}-\mathrm{OCH}_{3} \\
\text { for } \mathrm{VO}_{\mathbf{x}} / \mathrm{TiO}_{2}\end{array}$} & \multicolumn{2}{|c|}{$\mathrm{Ti}-\mathrm{OCH}_{3}$} & \multicolumn{2}{|c|}{$\begin{array}{c}\mathrm{V}-\mathrm{OCH}_{3} \\
\text { for } \mathrm{VO}_{\mathrm{x}} / \mathrm{ZrO}_{2}\end{array}$} & \multicolumn{2}{|c|}{$\mathrm{Zr}-\mathrm{OCH}_{3}$} \\
\hline Mode & Obs. & Calc. & Obs. & Calc. & Obs. & Calc. & Obs. & Calc. & Obs. & Calc. & Obs. & Calc. \\
\hline$v_{\text {as }}^{\text {CH3 }}$ & 2976 & 3024,3014 & 2990 & 3061,3036 & 2975 & 3016,3010 & - & 3019,2991 & 2975 & 3012,3008 & - & 3014,3002 \\
\hline$v_{\mathrm{s}}^{\mathrm{CH} 3}$ & 2932 & 2926 & 2960 & 2950 & 2935 & 2924 & 2924 & 2916 & 2929 & 2922 & 2925 & 2921 \\
\hline$\delta_{\mathrm{as}}{ }^{\mathrm{CH} 3}$ & 1448 & 1464,1461 & - & 1482,1475 & 1447 & 1471,1469 & - & 1476,1471 & 1448 & 1470,1468 & - & 1482,1476 \\
\hline$\delta_{\mathrm{s}}^{\mathrm{CH} 3}$ & 1436 & 1431 & - & 1440 & 1435 & 1432 & - & 1435 & 1437 & 1431 & - & 1445 \\
\hline$v^{\mathrm{CO}}$ & 1068 & 1059 & - & 985 & 1070 & 1029 & - & 1081 & 1060 & 1027 & - & 994 \\
\hline$v^{\mathrm{V}=\mathbf{0}}$ & 1028 & 985 & - & 1014 & 1020 & 1020 & - & 1025 & 1020 & 1017 & - & 1035 \\
\hline
\end{tabular}


Figure 2 Structures of methanol adsorption complexes.
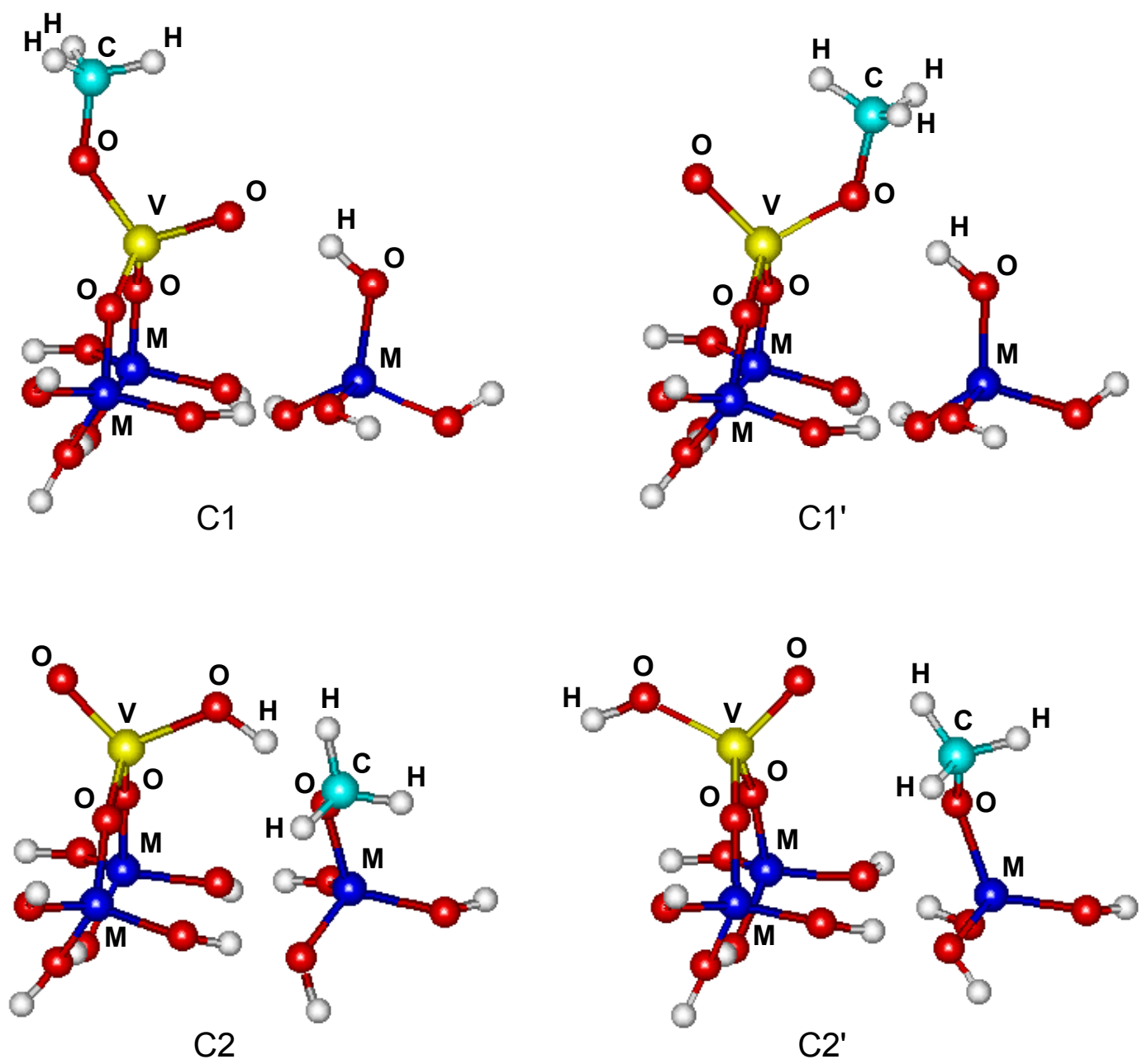
Table 4. Adsorption energies.

\begin{tabular}{|c|c|c|c|}
\hline $\mathrm{E}_{\mathrm{ads}}, \mathrm{kJ} / \mathrm{mol}$ & $\mathrm{VO}_{\mathrm{X}} / \mathrm{SiO}_{2}$ & $\mathrm{VO}_{\mathrm{x}} / \mathrm{TiO}_{2}$ & $\mathrm{VO}_{\mathrm{x}} / \mathrm{ZrO}_{2}$ \\
\hline Structure C1 & -88 & -91 & -96 \\
\hline Structure C1' & -85 & -93 & -97 \\
\hline Structure C2 & -80 & -48 & -60 \\
\hline Structure C2' & -32 & -33 & -57 \\
\hline
\end{tabular}


Figure 3 Comparison of calculated and observed methanol adsorption isobars for $\mathrm{VO}_{\mathrm{x}} / \mathrm{SiO}_{2}, \mathrm{VO}_{\mathrm{x}} / \mathrm{TiO}_{2}, \mathrm{VO}_{\mathrm{x}} / \mathrm{ZrO}_{2}$
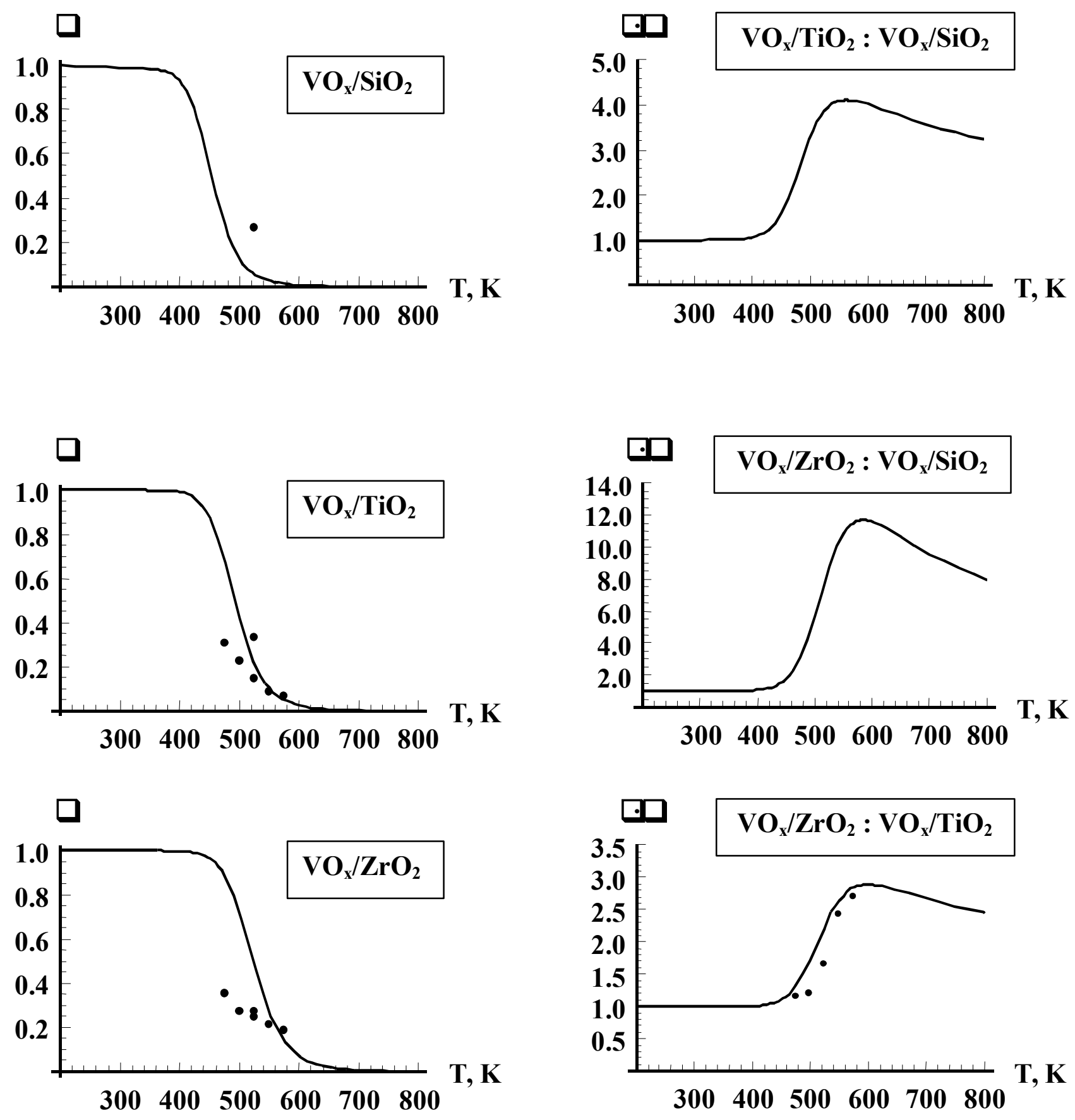
Figure 4 Reactant, transition, and product states involved in the oxidation of a methoxy group to formaldehyde

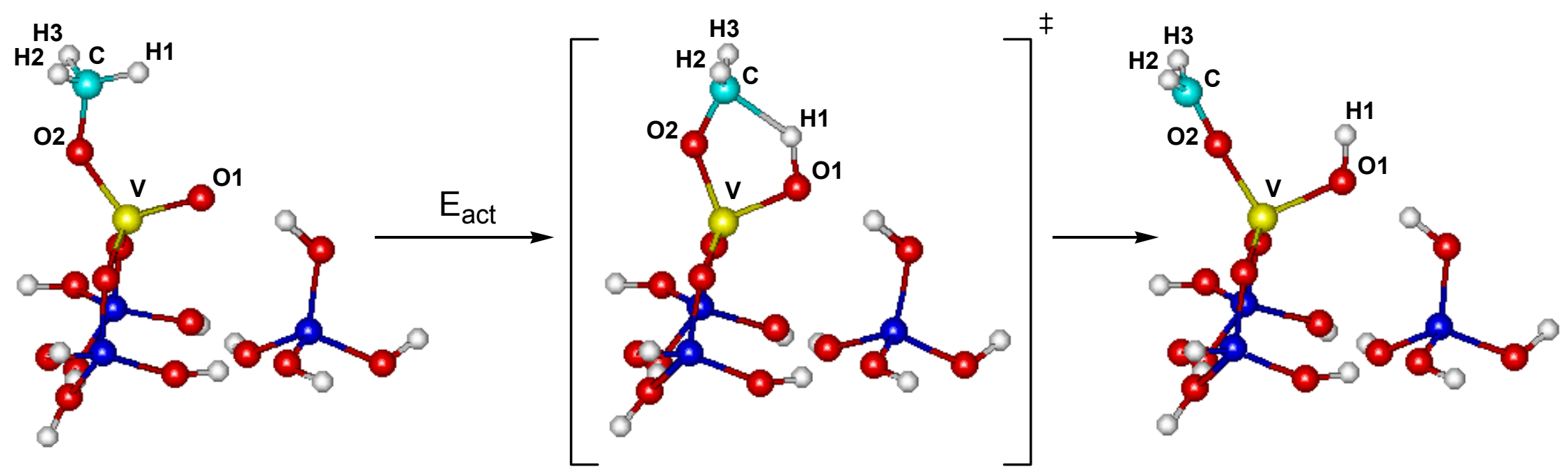


Table 5. Distances, angles, and Mulliken charges for reactant, transition, and product states involved in the oxidation of methoxy group to formaldehyde.

\begin{tabular}{|c|c|c|c|c|c|c|c|c|c|}
\hline & \multicolumn{3}{|c|}{$\mathbf{V O}_{\mathbf{x}} / \mathbf{S i O 2}$} & \multicolumn{3}{c|}{$\mathbf{V O}_{\mathbf{x}} / \mathbf{T i O}_{2}$} & \multicolumn{3}{c|}{$\mathbf{V O}_{\mathbf{x}} / \mathbf{Z r O}_{2}$} \\
\hline Parameter & Reactant & TS & Product & Reactant & TS & Product & Reactant & TS & Product \\
\hline O1-H1, $\AA$ & 2.937 & 1.109 & 0.979 & 3.156 & 1.100 & 0.973 & 3.046 & 1.094 & 0.980 \\
\hline V-O1, $\AA$ & 1.613 & 1.754 & 1.852 & 1.627 & 1.764 & 1.872 & 1.623 & 1.763 & 1.863 \\
\hline V-O2, $\AA$ & 1.740 & 1.761 & 1.797 & 1.749 & 1.765 & 1.803 & 1.752 & 1.765 & 1.796 \\
\hline O2-C, $\AA$ & 1.445 & 1.352 & 1.277 & 1.442 & 1.358 & 1.284 & 1.441 & 1.355 & 1.286 \\
\hline C-H1, $\AA$ & 1.095 & 1.687 & 3.401 & 1.096 & 1.725 & 3.627 & 1.095 & 1.737 & 3.540 \\
\hline C-O2-V, ${ }^{\circ}$ & 139.2 & 130.9 & 178.7 & 141.7 & 132.1 & 177.5 & 139.7 & 132.3 & 179.5 \\
\hline O1-V-O2, ${ }^{\circ}$ & 106.6 & 83.7 & 94.6 & 110.4 & 83.4 & 95.9 & 109.3 & 83.4 & 95.5 \\
\hline $\mathbf{q ( V ) , ~ a . u . ~}$ & 1.21 & 1.22 & 1.20 & 1.20 & 1.20 & 1.20 & 1.22 & 1.22 & 1.21 \\
\hline $\mathbf{q ( O 1 ) , ~ a . u . ~}$ & -0.45 & -0.66 & -0.75 & -0.49 & -0.70 & -0.80 & -0.48 & -0.69 & -0.78 \\
\hline $\mathbf{q ( O 2 ) , ~ a . u . ~}$ & -0.58 & -0.51 & -0.50 & -0.60 & -0.52 & -0.51 & -0.60 & -0.52 & -0.51 \\
\hline $\mathbf{q ( C ) , ~ a . u . ~}$ & -0.14 & -0.12 & 0.02 & -0.14 & -0.13 & 0.00 & -0.14 & -0.13 & -0.01 \\
\hline $\mathbf{q ( H 1 ) , ~ a . u . ~}$ & 0.18 & 0.32 & 0.38 & 0.18 & 0.33 & 0.39 & 0.18 & 0.32 & 0.38 \\
\hline $\mathbf{q ( H 2 ) , ~ a . u . ~}$ & 0.18 & 0.18 & 0.17 & 0.18 & 0.16 & 0.16 & 0.17 & 0.16 & 0.15 \\
\hline $\mathbf{q ( H 3 ) , ~ a . u . ~}$ & 0.18 & 0.18 & 0.17 & 0.18 & 0.16 & 0.16 & 0.17 & 0.16 & 0.15 \\
\hline
\end{tabular}


Table 6. Kinetic parameters.

\begin{tabular}{|c|c|c|c|}
\hline & $\mathrm{VO}_{\mathrm{x}} / \mathrm{SiO}_{2}$ & $\mathrm{VO}_{\mathrm{x}} / \mathrm{TiO}_{2}$ & $\mathrm{VO}_{\mathrm{x}} / \mathrm{ZrO}_{2}$ \\
\hline $\mathbf{E}_{\text {act }}, \mathrm{kJ} / \mathrm{mol}$ & 199 & 214 & 211 \\
\hline $\mathbf{E}_{\mathrm{app}}, \mathrm{kJ} / \mathrm{mol}^{\mathrm{a}}$ & 112 & 123 & 115 \\
\hline $\mathbf{k}_{\mathrm{app}}, \mathbf{s}^{-1} \mathbf{P a}^{-1}$ & $1.22 \times 10^{0}$ & $1.30 \times 10^{0}$ & $7.40 \times 10^{-1}$ \\
\hline $\mathbf{E}_{\text {app }}, \mathrm{kJ} / \mathrm{mol}$, experiment ${ }^{b}$ & 79 & 88 & 90 \\
\hline $\mathrm{k}_{\text {app }}, \mathrm{s}^{-1} \mathbf{P a}^{-1}$, experiment $^{b}$ & $1.26 \times 10^{2}$ & $3.32 \times 10^{5}$ & $6.57 \times 10^{5}$ \\
\hline
\end{tabular}

${ }^{\mathrm{a}} \mathrm{E}_{\mathrm{app}}=\mathrm{E}_{\mathrm{act}}+\Delta \mathrm{E}_{\mathrm{ads}}$

${ }^{\mathrm{b}}$ Ref. 1 